\title{
Electrochemical Determination of 6-Benzylaminopurine (6-BAP) Using a Single-wall Carbon Nanotube-dicetyl Phosphate Film Coated Glassy Carbon Electrode
}

\author{
Chunya Li \\ Key Laboratory of Analytical Chemistry of the State Ethnic Affairs Commission, College of Chemistry and Material Sciene, \\ South-Central University for Nationalities, Wuthan 430074,P.R.China.E-mail: li_chunya@163.com \\ Received April 12, 2006
}

\begin{abstract}
Herein, insoluble single-walled carbon nanotube (SWNT) was successfully dispersed into water in the presence of a special kind of surfactant-dicetyl phosphate (DCP), subsequently, a SWNT-DCP composite film coated glassy carbon electrode (GCE) was fabricated. The electrochemical behaviors of 6-benzylaminopurine (6$\mathrm{B} \Lambda \mathrm{P}$ ) at the unmodified GCE and SWNT-DCP modified GCE were examined. It is found that the SWNT-DCP modified GCE remarkably enhances the oxidation peak current of $6-\mathrm{B} \Lambda \mathrm{P}$, indicating great potential in the determination of trace level of $6-\mathrm{B} \Lambda \mathrm{P}$. Finally, a sensitive and simple voltammetric method with a good linear relationship in the range of $5.0 \times 10^{-8} \sim 2.5 \times 10^{-6} \mathrm{~mol} / \mathrm{L}$, was developed for the determination of $6-\mathrm{B} \Lambda \mathrm{P}$. The detection limit is as low as $2.0 \times 10^{-8} \mathrm{~mol} / \mathrm{L}$ for $3-\mathrm{min}$ accumulation. This newly-proposed method was successfully demonstrated with practical samples.
\end{abstract}

Key Words : Single-walled carbon nanotube, Dicetyl phosphate, 6-Benzylaminopurine, Modified electrode, Electroanalysis

\section{Introduction}

6-Benzylaminopurine (6-BAP, Fig. 1) is derived from adenine, substituted on the amino group in the position 6 . It is a common model compound for one of the most important classes of plant hormones-cytokinins. ${ }^{1-3}$ Therefore, the development of a rapid, simple and sensitive method for the determination of 6-BAP is of great importance and interest.

At present, the most commonly-used method for the determination of 6-BAP is UV photometry. ${ }^{4}$ However, the sensitivity of UV is limited, and not suitable for trace level of 6-BAP. Otherwise, high performance liquid chromatography (HPLC) was employed to detect 6-BAP in bean sprout." From the point of molecular structure of 6-BAP, it contains purine group, which can be oxidized or reduced under proper conditions. Therefore, a few papers regarding the electrochemical behavior and voltammetric determination of 6-BAP have also been published ${ }^{67}$ To the best of our knowledge, determining 6-BAP using single-wall carbon nanotube (SWNT)-dicetyl phosphate (DCP) composite film modified GCE has not been reported.

Since their discovery by Ijjima in $1991,{ }^{8}$ CNTs have

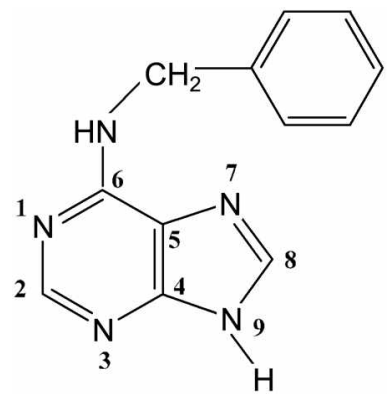

Figure 1. Chemical structure of 6-BAP. drawn increasing attention on account of their unique structure and extraordinary properties. Generally, carbon nanotubes (CNTs) mainly consist of single-wall carbon nanotube (SWNT) and multi-wall carbon nanotube (MWNT). The subtle electronic properties suggest that CNTs have the ability to promote electron transfer, resulting in wide applications in electrochemistry. ${ }^{9-12}$ However, CNTs are almost insoluble to all solvents, ${ }^{13}$ which heavily limits their applications in electroanalysis, especially in the fabrication of CNTs-modified electrodes.

In the current work, insoluble SWNT was easily and successfully dispersed into water in the presence of a specific surfactant with two hydrophobic C-H chains: dicetyl phosphate (DCP). As a result, a stable and uniform SWNT-DCP aqueous suspension was achieved. Finally, a SWNT-modified glassy carbon electrode (GCE) was fabricated via waterevaporation. The electrochemical response of $6-\mathrm{BAP}$ on the SWNT-DCP modified GCE was detailedly investigated, revealing that SWNT-DCP cast film can remarkably enhance the electro-oxidation signal of 6-BAP as well as its determining sensitivity. Based on this, a simple and sensitive electrochemical method was developed for the determination of 6-BAP.

\section{Experimental Section}

Reagents. $1.0 \times 10^{-3} \mathrm{~mol} / \mathrm{L}$ 6-BAP stock solution was prepared through dissolving 6-BAP (Aldrich) into $0.1 \mathrm{~mol} / \mathrm{L}$ $\mathrm{NaOH}$, and stored at $4{ }^{\circ} \mathrm{C}$ for a week. The $6-\mathrm{BAP}$ working solutions with different concentration were obtained by dilution of the stock solution, and used daily.

The single-walled carbon nanotube (SWNT) with purity $>95 \%$ was obtained from Chengdu Organic Chemicals Co., Lit, Chinese Academy Sciences. Then, SWNT was refluxed 
in concentrated $\mathrm{HNO}_{3}$ for $10 \mathrm{~h}$ to causes segmentation and carboxylation. ${ }^{14}$ Dicetyl phosphate (DCP) was purchased from Sigma.

Apparatus. All the electrochemical measurements were carried out with a $\mathrm{CHI} 660 \mathrm{~A}$ Electrochemical Workstation (CH Instrument, Austin, USA). A conventional threeelectrode system, including a SWNT-DCP modified GC working electrode, a saturated calomel reference electrode (SCE) and a Pt wire counter electrode, was employed.

Fabrication of SWNT-DCP film-coated GCE. The SWNT-DCP suspension was achieved via dispersing a 5-mg SWNT and 5 -mg DCP into a $5 \mathrm{~mL}$ of redistilled water by 20-min ultrasonication agitation. Prior to modification, the GCE was mechanically polished with alumina paste of different grades to mirror finish, rinsed and sonicated in redistilled water for $3 \mathrm{~min}$. Finally, the GCE was coated with $10.0 \mu \mathrm{L}$ of the SWNT-DCP suspension and allowed to evaporate water at room temperature in the air. The DCPfilm coated GCE was prepared by the same procedure explained above but without SWNT.

Procedure. Unless otherwise stated, $0.1 \mathrm{~mol} / \mathrm{L}$ phosphate buffer with $\mathrm{pH}=7.0$ was used as medium for the detemination of 6-BAP. The accumulation step was carried out under open-circuit while stirring the solution for $3 \mathrm{~min}$. After that, the differential pulse voltammograms from 0.50 to $1.10 \mathrm{~V}$ were recorded after 15-s quiescence, and the peak current at about $0.92 \mathrm{~V}$ was measured. Prior to and after each measurement, the SWNT-DCP modified GCE was activated by five successive cyclic voltammetric sweeps between 0.00 $\mathrm{V}$ to $1.20 \mathrm{~V}$ at $100 \mathrm{mV} / \mathrm{s}$ in the blank medium to give a reproducible electrode surface.

\section{Results and Discussion}

Electrochemical behavior of 6-BAP. The electrochemical behavior of 6-BAP was examined using cyclic voltammetry (CV). Figure 2 shows the successive cyclic voltammograms of $5.0 \times 10^{-6} \mathrm{~mol} / \mathrm{L}$ 6-BAP on the SWNT-DCP modified GCE in $0.1 \mathrm{~mol} / \mathrm{L}$ phosphate buffer $(\mathrm{pH} 7.0$ ). During the first anodic potential sweep from 0.40 to $1.20 \mathrm{~V}$, a well-defined and very sensitive oxidation peak appears at $0.94 \mathrm{~V}$. On the following reverse scan from 1.20 to $0.40 \mathrm{~V}$, there is no corresponding reduction peak, suggesting that the electrode process of 6-BAP on the SWNT-DCP modified GCE is totally irreversible.

As can be seen from Figure 2, the oxidation peak current gradually decreases as increasing the number of cyclic potential sweeps. The decrease in peak current may be caused by the fact that the adsorption of oxidative product occurs at electrode surface. Therefore, the electrode surface was passivated, which retards the electro-oxidation of 6BAP. Thus, the oxidation peak current in the first anodic sweep is recorded for the analysis of 6-BAP in the following studies.

In order to show the unique properties and promising potential of SWNT-DCP modified GCE in the determination of 6-BAP. the electrochemical behaviors of 6-BAP at three

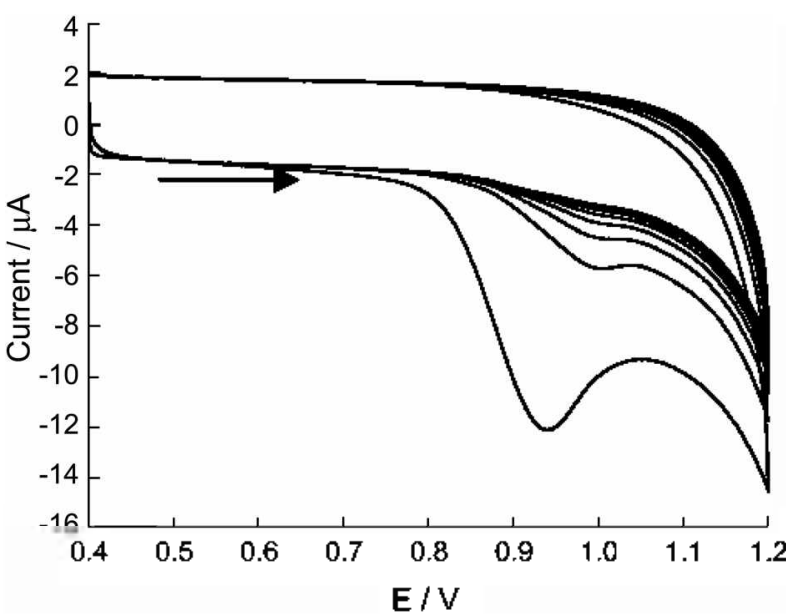

Figure 2. Successive cyclic voltammograms of $5.0 \times 10^{-6} \mathrm{~mol} / \mathrm{L} 6-$ BAP at SWNT-DCP modified GCE in $0.1 \mathrm{~mol} / \mathrm{L}$ phosphate buffer $(\mathrm{pH} 7.0)$. Scan rate: $100 \mathrm{mV} / \mathrm{s}$.

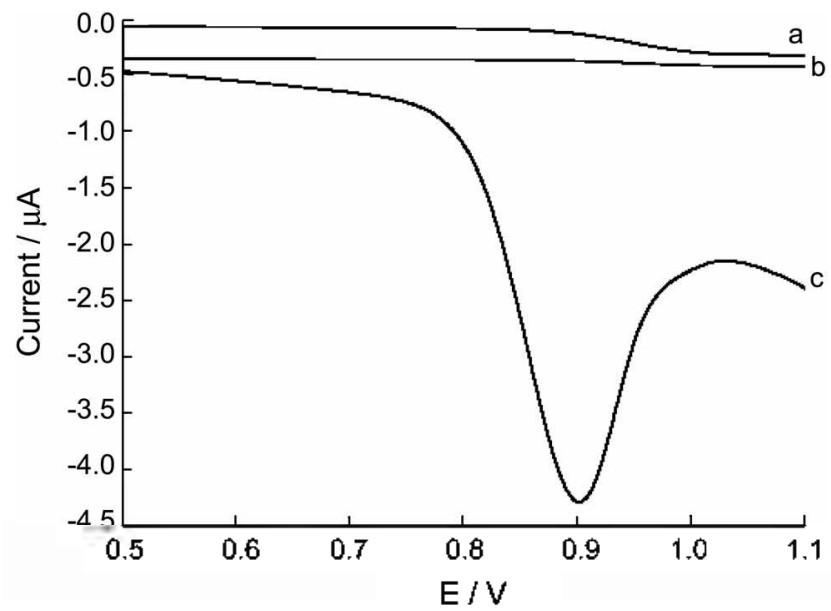

Figure 3. DP voltaminograins of $5.0 \times 10^{-7} \mathrm{~mol} / \mathrm{L} 6-\mathrm{B} A \mathrm{P}$ in 0.1 mol/L phosphate buffer (pH 7.0) after 3-inin open-circuit accumulation. (a): at unmodified GCE, (b): at DCP film modified GCE, and (c): at SWNT-DCP modified GCE. The DPV parameters: pulse anplitude $=50 \mathrm{mV}$, scan rate $=20 \mathrm{mV} / \mathrm{s}$, pulse width $=50 \mathrm{~ms}$.

different kinds of working electrodes (i.e. bare GCE, DCPmodified GCE and SWNT-DCP film coated GCE) were compared by differential pulse voltammetry (DPV). The comparisons are illustrated in Figure 3 with DPV parameters: pulse amplitude $=50 \mathrm{mV}$, scan rate $=20 \mathrm{mV} / \mathrm{s}$, pulse width $=50 \mathrm{~ms}$, accumulation time $=3 \mathrm{~min}$. At an unmodified GCE, an oxidation peak at $1.06 \mathrm{~V}$ is observed for $5.0 \times 10^{-7} \mathrm{~mol} / \mathrm{L} 6-\mathrm{BAP}$, the peak current is very low (curve a). At the DCP-film coated GCE, the oxidation peak current conversely decreases greatly under identical conditions (curve b). DCP can form a perfect thin film on GCE surface, and thus blocks the mass transportation and electron transfer of 6-BAP, so the peak current decreases. However, the oxidation peak current of $5.0 \times 10^{-7} \mathrm{~mol} / \mathrm{L}$ 6-BAP increases significantly (about 15 times) at the SWNT-DCP modified GCE; meanwhile, the oxidation peak potential shifts negatively to $0.90 \mathrm{~V}$ (curve $\mathrm{c}$ ), compared with those at the bare 
and DCP-modifjed GCEs. The peak current enhancement and negative shift of oxidation peak potential are undoubtedly attributed to the unique characteristics of SWNT film such as high surface area and strong adsorptive abilities. In brief, the SWNT-DCP film coated GCE greatly improves the sensitivity of determination of 6-BAP.

Influence of supporting electrolyte. The electrochemical responses of 6-BAP at SWNT-DCP composite film modified GCE have been examined in several electrolytes, including phosphate buffer of $\mathrm{pH} 5.0-8.0$, Britton-Robison buffer of $\mathrm{pH} 2.0-12.0$, acetate buffer of $\mathrm{pH} 3.5-5.5$ (each 0.1 $\mathrm{mol} / \mathrm{L}$ ). In those media, it is found that the oxidation peak is best-shaped and the peak current is highest in $\mathrm{pH} 7.0$ phosphate buffer. Moreover, the background current is relatively low. Therefore, $0.1 \mathrm{~mol} / \mathrm{L}$ phosphate buffer at $\mathrm{pH}$ 7.0 was chosen for further studies.

In addition, the relationship between $\mathrm{pH}$ value and the oxidation peak potential $\left(\mathrm{E}_{\mathrm{p} a}\right)$ has also been studied. The $\mathrm{pH}$ value strongly affects $\mathrm{E}_{\mathrm{pa}}$ of 6-BAP. $\mathrm{E}_{\mathrm{pa}}$ shifts toward more negative potentials as $\mathrm{pH}$ increasing from 5.0 to 8.0 , and a good linear relationship ( $\mathrm{E}_{\mathrm{pu}}=1.34-0.057 \mathrm{pH}, \mathrm{E}_{\mathrm{pu}}$ in $\mathrm{V}$ ) was observed. The slope of $-57 \mathrm{mV} / \mathrm{pH}$ indicates that the number of protons and electrons involved in the oxidation of 6-BAP is equal. This is in good agreement with the previous result that the rate-detemining step of 6-BAP oxidation is a two-electron and two-proton process. ${ }^{15}$

Effect of the volume of SWNT-DCP suspension. Generally speaking, the thickness of the SWNT-DCP cast film on GCE surface, which determined by the volume of SWNTDCP suspension, has certain effect on the current response of 6-BAP. There is no exception in this work. Figure 4 depicts the variation of oxidation peak current of $6-\mathrm{BAP}$ as a function of the volume of SWNT-DCP suspension. When the amount of SWNT-DCP suspension increases from 0.0 to $5.0 \mu \mathrm{L}$, the oxidation peak current increases notably, but with further increased the amount of SWNT-DCP suspension to $15.0 \mu \mathrm{L}$, the oxidation peak current increases slightly. If the amount of SWNT-DCP suspension exceeds $15.0 \mu \mathrm{L}$,

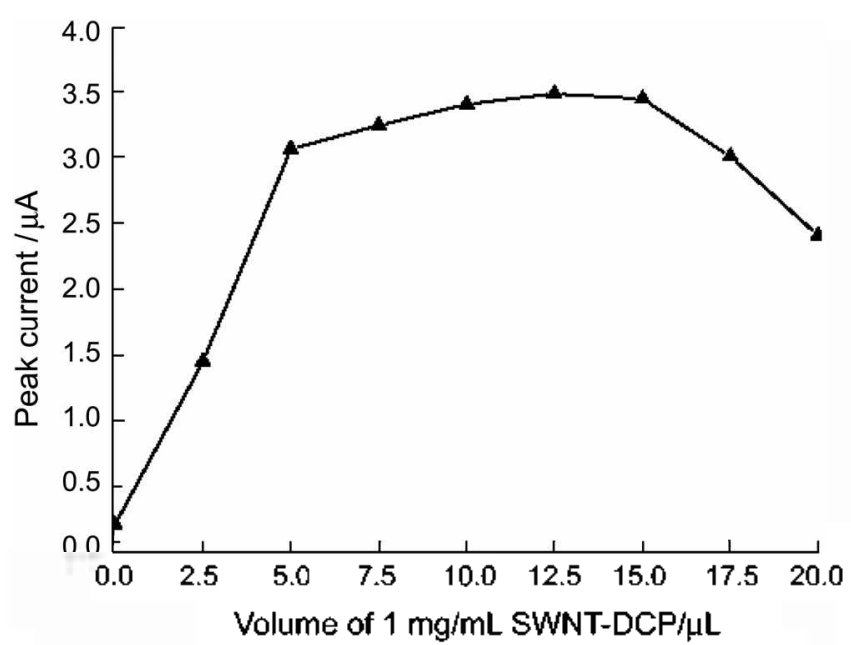

Figure 4. Effect of the volume of the SWNT-DCP suspension on the oxidation peak current of $5.0 \times 10^{-7} \mathrm{~mol} / \mathrm{L} 6-\mathrm{B} \wedge \mathrm{P}$. Other conditions are the same as in Fig. $3 \mathrm{c}$.

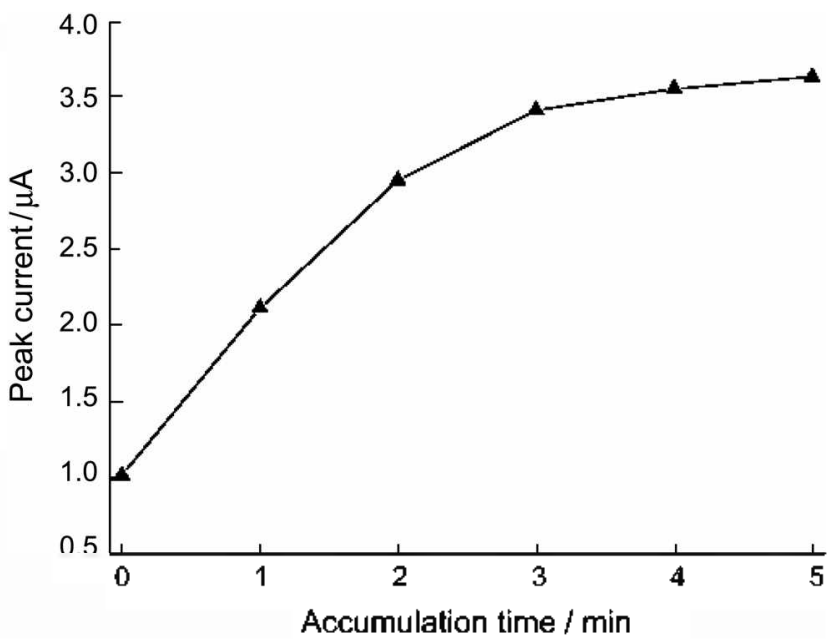

Figure 5. Influence of accumulation time on the oxidation peak current of $5.0 \times 10^{-7} \mathrm{~mol} / \mathrm{L}$ 6-BAP. Other conditions are the same as in Fig. 3c.

the oxidation peak current conversely shows gradual decline. DCP, an insulator, lowers the electrical conductivity of SWNT film and the electron-transfer rate of 6-BAP. Hence, the peak current decreases when the SWNT-DCP film is too thick. In the current work, $10.0 \mu \mathrm{L}$ of $1 \mathrm{mg} / \mathrm{mL}$ SWNT-DCP suspension was used to cast GCE surface.

Influence of scan rate. The influence of scan rate $(v)$ on the oxidation peak current $\left(\mathrm{i}_{\mathrm{pa}}\right)$ was investigated by linear sweep voltammetry (LSV). It is found that $i_{p 2}$ of $5.0 \times 10^{-6}$ $\mathrm{mol} / \mathrm{L}$ 6-BAP without accumulation increases linearly with the square root of $v$, indicating that the oxidation of 6-BAP at the SWNT-DCP film-coated GCE is diffusion-controlled.

Accumulation conditions. The influence of accumulation time on the oxidation peak current of 6-BAP was shown in Figure 5. At the SWNT-DCP modified GCE, the oxidation peak current of $5.0 \times 10^{-7} \mathrm{~mol} / \mathrm{L} 6-\mathrm{BAP}$ increases greatly with extending accumulation time from 0 to $3 \mathrm{~min}$. When the time is beyond $3 \mathrm{~min}$, the oxidation peak current increases slightly and the plots become curved, the curvature presumably indicating the limiting value of the amount of 6$\mathrm{BAP}$ on the electrode surface has been achieved.

Calibration curve. The dependence of oxidation peak current on 6-BAP concentration was examined in the 0.1 $\mathrm{mol} / \mathrm{L}$ phosphate buffer $(\mathrm{pH} 7.0$ ) by DPV. The linear concentration range was found to occur from $5.0 \times 10^{-8}$ to $2.5 \times 10^{-6} \mathrm{~mol} / \mathrm{L}$, and the detection limit is found to be $2.0 \times$ $10^{-8} \mathrm{~mol} / \mathrm{L}$ after $3-\mathrm{min}$ accumulation.

The reproducibility was also evaluated by successive measuring the same $5.0 \times 10^{-7} \mathrm{~mol} / \mathrm{L} 6-\mathrm{BAP}$ solution for 10 times at a single SWNT-DCP modified electrode. After each measurement, the modified electrode was thoroughly rinsed with water, transferred into the blank electrolyte and scanned in the range of 0.40 to $1.20 \mathrm{~V}$ for 5 cycles to remove any adsorbates. The relative standard deviation (RSD) of $5.2 \%$ indicates excellent repeatability.

The long-term stability of the SWNT-DCP modified-GCE was tested by measuring the current response at a fixed 6- 
Table 1. Interferences of foreign species on the oxidation peak current of $5.0 \times 10^{-7} \mathrm{~mol} / \mathrm{L}$ 6-BAP. Accumulation time $=3 \mathrm{~min}$; pulse amplitude $=50 \mathrm{mV}$, scan ratc $=20 \mathrm{mV} / \mathrm{s}$, pulse width $=50 \mathrm{~ms}$

\begin{tabular}{|c|c|}
\hline Foreign species & $\begin{array}{c}\text { Tolerance } \\
\text { level }(\mathrm{mol} / \mathrm{L})^{*}\end{array}$ \\
\hline $\mathrm{Ca}^{2}, \mathrm{Mg}^{2}, \mathrm{Zn}^{2}, \mathrm{Al}^{3}, \mathrm{Cd}^{2}, \mathrm{~Pb}^{2}, \mathrm{Fe}^{3}, \mathrm{Cu}^{2}$ & $5.0 \times 10^{-4}$ \\
\hline $\begin{array}{l}\text { Dopamine (DA), ascorbic acid (AA), uric acid (UA), } \\
\text { xanthine (XA), vitamin } \mathrm{B}_{6} \text {, cystine, serine, citrulline, } \\
\text { tryptophane, benzoic acid, vitamin E }\end{array}$ & $2.5 \times 10^{-5}$ \\
\hline Guanine & $1.0 \times 10^{-5}$ \\
\hline
\end{tabular}

For 5\% etror

Table 2. Determination of $6-\mathrm{B} \wedge \mathrm{P}$ in samples using SWNT-DCP modified GCE

\begin{tabular}{cccc}
\hline Samples & $\begin{array}{c}\text { Detected by SWNT-DCP } \\
(\text { mol/L) }\end{array}$ & $\begin{array}{c}\text { RSD } \\
(\%)\end{array}$ & $\begin{array}{c}\text { Recovery } \\
(\%)\end{array}$ \\
\hline A & $4.82 \times 10^{-7}$ & 5.2 & 103.2 \\
B & $8.90 \times 10^{-7}$ & 4.8 & 100.8 \\
C & $6.84 \times 10^{-7}$ & 5.1 & 98.6 \\
D & $8.12 \times 10^{-7}$ & 5.0 & 102.4 \\
\hline
\end{tabular}

BAP concentration of $5.0 \times 10^{-7} \mathrm{~mol} / \mathrm{L}$ over a period of 2 weeks. The SWNT-DCP modified-GCE was used daily and stored in air. After 2 weeks, the current response only decreases $5.7 \%$, suggesting that the SWNT-DCP modifiedGCE reported in this work has long-term stability.

Interferences. To evaluate the potential effect of foreign species on the determination of 6 -BAP at $5.0 \times 10^{-7} \mathrm{~mol} / \mathrm{L}$ level, a systematic study was carried out under the aboveoptimized conditions. The peak currents of 6-BAP in the absence and presence of foreign species were measured by DPV, respectively, and the error was consequently obtained. The results are listed in Table 1. It is found that $5.0 \times 10^{-4}$ $\mathrm{mol} / \mathrm{L} \mathrm{Ca}{ }^{2+}, \mathrm{Mg}^{2+}, \mathrm{Zn}^{2+}, \mathrm{Al}^{3+}, \mathrm{Cd}^{2+}, \mathrm{Pb}^{2+}, \mathrm{Fe}^{3+}, \mathrm{Cu}^{2+}, 2.5 \times$ $10^{-5} \mathrm{~mol} / \mathrm{L}$ dopamine (DA), ascorbic acid (AA), uric acid (UA), xanthine (XA), vitamin $B_{6}$, cystine, serine, citrulline, tryptophane, benzoic acid, vitamin $\mathrm{E}$, and $1.0 \times 10^{-5} \mathrm{~mol} / \mathrm{L}$ guanine, almost do not interfere with the oxidation signal of 6-BAP (signal change below 5\%). However, adenine has relatively obvious interference on the determination of 6BAP since they have similar molecular structure.

Analysis of 6-BAP in samples. The surface of some fruits were cleaned and then squirted with $2 \mathrm{~mL}$ of $1.0 \times 10^{-3} \mathrm{~mol} /$ L 6-BAP stock solution, respectively. After 1 hour, they were respectively dipped into $100 \mathrm{~mL}$ of $\mathrm{pH} 7.0$ phosphate buffer containing $10 \mathrm{~mL} \mathrm{CH} \mathrm{CH}_{3} \mathrm{OH}$ for $30 \mathrm{~min}$ to obtain 6-
BAP sample solutions. After that, $10 \mathrm{~mL}$ of the sample solution was added into the electrochemical cell, and then the electrochemical measurement described in the procedure was performed to determine 6-BAP content under the optimum conditions. The content of 6-BAP was determined by the standard addition method, and the results shown in Table 2. Furthermore, in order to establish the suitability of the proposed method, known amounts of the standard 6BAP were added into the analytical solution, and the same procedure was applied. The recoveries indicate that the accuracy of this proposed voltammetric method is excellent. From the experimental results, it is very clear that this novel SWNT-DCP film coated GCE has great potential for practical sample analysis.

\section{Conclusion}

Owing to the unique properties of SWNT, the SWNTDCP composite film facilitates the oxidation of 6-BAP, greatly enhances the oxidation peak current of 6-BAP and lowers its oxidation overpotential. Based on this, a simple, rapid and sensitive electrochemical method was developed for the determination of 6-BAP.

\section{References}

I. Clifford, P. E.; Pentland, B. S.; Baylis, A. D. J. Agric. Sci, 1992, 119,7l.

2. Polando, M. C.; Ruiz, M. L. Plant Cell Reports 1997, 17, 22.

3. Barclay, G. F.; McDavid, C. R. Scientia Horticulturae 1998, 72, 81.

4. Glossary of Chinese Commodity Fascicule of Chemical Reagent; Business Publishing: 1994; 655.

5. Li, X. P.; Chen, X. H.; Yao, X. P.; Jin, M. C.; Jiang, J. W. Chinese Journat of Heall Laboratory Technology 2005, 15, 149.

6. Zhao, G; Liu, K.; Lin, S.; Liang, J.; Guo, X.; Zhang, Z. Microchint Acta 2003, 143,255.

7. Tarkowska, D.; Kotoucek, M.; Dolezal, K. Coll. Czech. Chem. Commin, 2003, 68, 1076.

8. Jijima, S. Nafure 1991, 54, 56.

9. Britto, P. J.; Santhanam, K. S. V; Ajayan, P. M. Bioelectrochen. Bioenerg. 1996, 41, 121 .

10. Musamech. M.; Wang, J.; Merkoci, A.; Lin. Y. H. Electrochem. Commin, 2002, 4, 743.

11. Wu, K. B.; Fei, J. J.; Hu, \$. \$. Anal. Biochem. 2003, 3/8, 100.

12. Fei, J. J.; Wu, K. B.; Yi, L, H.; Li, J. N. Bull. Korean Chem. Soc. 2005, 26, 1403.

13. Wang, J.; Musameh, M.; Lin, Y. H. J. Am. Chem. Soc. 2003, 125 , 2408.

14. Tsang, S. C.; Chen, Y. K.; Harris, P. J. E.; Green, M. L. H. Nature 1994, 372, 159.

15. Sun, D.; Zhang, H. J. Anal. Chim. Acta 2006, 557, 64. 